\title{
The Woes of Economic Burden of Traumatic Brain Injury (TBI) Cases Borne by Public Sector Hospital of Pakistan
}

\author{
SYED SHAHZAD HUSSAIN, ${ }^{1}$ USMAN AHMAD KAMBOH, ${ }^{1}$ MUHAMMAD ASIF RAZA ${ }^{1}$ \\ MADIHA KANWAL, ${ }^{1}$ SAMAN SHAHID, ${ }^{2}$ NAVEED ASHRAF ${ }^{1}$ \\ ${ }^{1}$ Department of Neurosurgery, Jinnah Hospital \\ ${ }^{2}$ National University of Computer \& Emerging Sciences (NUCES), Lahore, Pakistan. \\ DOI: https://doi.org/10.36552/pjns.v23i3.356
}

\begin{abstract}
Objectives: Traumatic brain injury (TBI) a major portion of trauma worldwide, which holds a significant financial burden for the patients. We highlighted the role of public sector hospitals in sharing the major financial burden of severely head injured patients in a resource constrained economically striving country.

Materials and Methods: The study was conducted in the Neurosurgery department of Jinnah Hospital, Lahore, Pakistan. 70 patients with moderate to severe TBI cases above one year of age were included. The data was analyzed for the cost estimation for the period of six months, for the following heads: 1) hospital cost per day, 2) ICU setup cost per day, and 3) salaries of hospital staff per day.

Results: There were 53 cases of moderate injury and 17 cases of severe injury. Mean hospital stay was 14 days, minimum number of stay was 2 days and the maximum number of stay was 124 days in six months. Overall, in six months, per day cost of hospital bills head was Rs. 42,333/\$263/€ 238. For the ICU setup head, the total cost was Rs. 17,9923/\$1130/€ 1016 per day. The salary head's total cost was Rs. 2573/\$16.06/€ 14.44. The grand total of all heads, (bills, ICU setup \& salaries) was Rs. 22,482,29/\$1409/€ 1270.

Conclusion: We evaluated the cost effectiveness of the Neurocritical care unit of a public sector hospital who provides the best possible health care facilities at a cheaper rate as compared to developed countries. We are highlighting the economic burden borne by the developing country's government.
\end{abstract}

Keywords: Traumatic Brain Injury (TBI), ICU setup cost, Hospital cost, Salaries of medical staff, TBI Financial burden.

\section{INTRODUCTION}

Traumatic brain injury (TBI) holds a major portion of trauma worldwide, which leads to permanent deficit or even death. ${ }^{1}$ In this era of rapid globalization, there is a continuous variation in the economic strategy stresses which leads to the diverse allocation of their respective GDPs (gross-domestic products) for health and for other sectors. The GDP for health in US is $17 \%$ per year, which is about six times that of Pakistan. Pakistan is one of the developing countries of South Asia. We can imagine from these values that the health care facilities in Pakistan is already jeopardize. Youth plays a pivotal role in the economic progress of a developing country. Road traffic accidents poses a major threat to the young population. The loss of youth is not only a loss of family, but also for the nation, because they are in the economically productive age of their life. Most of the effort on documented assessment of TBI impact on the economy is a sparse..$^{2-5}$ The head injuries have a significant impact on people and society as it is a major health issue. ${ }^{6}$ It had been emphasized in evaluating the cost of injuries to estimate the economic or financial burden borne by the society and government with the help of physicians and surgeons. ${ }^{6}$ The economic consequences of road traffic accidents and TBI is scarce and it is the need of time to establish an integrated knowledge on the woes of economic 
burden borne by the public sector hospitals in order to establish a standard health care policy, scarce resource allocation and future direction for the development of an efficient healthcare and rehabilitation dispensation. The purpose of our study was to highlight the role of public sector hospitals in sharing the major burden of severely head injured patients in a resource constrained economically striving country. The survivors of TBI almost always experience some level of disability that affects their quality of life ${ }^{1}$. Almost 33 billion euros were spent in Europe on TBI patients. ${ }^{7}$ Traumatic brain injury (TBI) is although less common than backaches and arthritis, but it includes more per capita direct and indirect health costs (more than $\$ 200$ billion per year), because it is often led by disabilities. ${ }^{8}$

\section{MATERIAL AND METHODS Study Design and Sampling}

We conducted a prospective study in Neurosurgery department of Jinnah hospital, Lahore from January 2018 to July 2018. Non probability consecutive sampling technique. A total of 70 patients were enrolled in our study and the data was collected in a Proforma. Total 70 enrolled TBI patients were included in this study with the following criteria.

\section{Inclusion Criteria}

The TBI patients included with age $>1$ year for both genders. Cases of moderate and severe traumatic brain injury patients were included, who were admitted through the emergency department of the hospital.

\section{Exclusion Criteria}

Cases with following conditions were excluded: polytrauma, comorbidities, mild TBI, admissions from other ICUs and those who left against medical advice.

\section{Data Analysis}

The data was analyzed for the cost estimation for the period of six months, for the following three major heads: 1) hospital cost, 2) intensive care unit (ICU) cost, and 3) salaries of hospital staff. The head of 'hospital cost' included all necessary neurocritical care medicines/neuromedicines (fluids, anti-epileptics, Mannitol, etc, sedative \& paralytics, analgesics, antibiotics, nutrition, miscellaneous drugs and routine lab investigations etc. ) used for all patients in six months, utility bills per bed-per day, hospital laundry per bed-per day, maintenance service charges (e.g., biomedical department, maintenance workshops etc.) per day and miscellaneous items (e.g., expenses of patients' attendants). The second head of expenses covered the ICU setup, which includes: 8ICU beds, 8 ICU ventilators and 8 ICU monitors. The last head included the salaries of all following associated hospital staff: duty doctors, nurses, paramedical and consultants.

\section{RESULTS}

Out of 70 patients, there were 50 male patients and 20 female patients, with age between 2 to 80 years. The median age of the patients was 31 years. The minimum Glasgow coma score (GCS) was 4T, whereas, the maximum was 13 . There were 53 cases of moderate injury and 17 cases of severe injury.

The total cost during six months of all relevant hospital expenses, including ICU (intensive care unit) and HDU (high dependency unit) was calculated for the three main heads as mentioned. Mean hospital stay was 14 days, minimum number of stay was 2 days and the maximum number of stay was 124 days in six months.

Table 1, describes the first head cost which included medicines, bills, maintenance, etc. Total cost of Neurocritical drugs and routine investigations for all patients in six months was Rs. 39,65,978/\$ 24,787/€ 22,371 . Overall, in six months, per day cost of this head was Rs. 42,333/\$ 263.05/€ 238.66. For the second head, which included ICU setup (beds, ventilators and monitors), the total cost was Rs. 17,9923/\$1129.91/€ 1016.10 per day (Table 2). The purchased cost of eight beds, ventilators and monitors for the ICU setup is mentioned in Table 2.

Table 3 describes, the last head, which includes the medical personnel salaries. The total expenditure of salaries was Rs. 2573/\$16.06/€ 14.44. The grand total of all heads, (bills, ICU setup \& salaries) was Rs. 22,48229/\$1409.02/€1269.20.

Table 1: Hospital Cost Estimation (Six Months).

\begin{tabular}{|l|c|c|c|}
\hline Hospital Bills (Per Bed/Case-Per Day) & Cost in (Rupees) & Cost in (US \$) & Cost in (Euros) \\
\hline Neurocritical Medicines and Investigations & 22,033 & 137 & 124 \\
\hline
\end{tabular}


Syed Shahzad Hussain, et al

\begin{tabular}{|c|c|c|c|}
\hline Utility Bills & 2650 & 16 & 15 \\
\hline Hospital Laundry & 50 & 0.3 & 0.28 \\
\hline Maintenance Services Charges & 17000 & 106 & 96 \\
\hline Misc. Expenses per day (e.g. Attendants) & 600 & 3.75 & 3.38 \\
\hline Grand Total & 42,333 & 263.05 & 238.66 \\
\hline
\end{tabular}

Table 2: ICU Setup Costs.

\begin{tabular}{|l|c|c|c|}
\hline Purchased ICU Setup & Purchased Cost (Rupees) & Purchased Cost (US \$) & Purchased Cost (Euros) \\
\hline Beds (8) & $88,78,344$ & 55,489 & 50,080 \\
\hline Ventilators (8) & $30,06,64,160$ & $18,79,151$ & $16,95,984$ \\
\hline Monitors (8) & $1,88,13,900$ & $1,17,586$ & $1,06,125$ \\
\hline Grand Total & $\mathbf{3 2 8 , 3 5 6 , 4 0 4}$ & $\mathbf{2 0 5 , 2 2 2 6}$ & $\mathbf{1 8 5 , 2 1 8 9}$ \\
\hline Purchased ICU Setup/Per Day & Cost Per Day (Rupees) & Cost Per Day (US \$) & Cost Per Day (Euros) \\
\hline Beds (8) & 4865 & 30.52 & 27.47 \\
\hline Ventilators (8) & 164750 & 1033.72 & 930.422 \\
\hline Monitors (8) & 10308 & 65.67 & $\mathbf{1 1 2 9 . 9 1}$ \\
\hline Grand Total & $\mathbf{1 7 9 9 2 3}$ & $\mathbf{1 0 1 6 . 1 0 2}$ \\
\hline
\end{tabular}

Table 3: Salaries of the Hospital Staff.

\begin{tabular}{|l|c|c|c|}
\hline Staff Salaries (Per Day) & Cost in (Rupees) & Cost in (US \$) & Cost in (Euros) \\
\hline Duty Doctor & 291 & 1.8 & 1.64 \\
\hline Staff/Nurses & 833 & 5.2 & 4.7 \\
\hline Paramedical & 1054 & 6.6 & 5.9 \\
\hline Consultant & 395 & 2.46 & 2.2 \\
\hline Grand Total & $\mathbf{2 5 7 3}$ & $\mathbf{1 6 . 0 6}$ & $\mathbf{1 4 . 4 4}$ \\
\hline
\end{tabular}

Table 4: Grand Total of All Heads (Six Months).

\begin{tabular}{|l|c|c|c|}
\hline Cost of Head (Per Day) & Cost in (Rupees) & Cost in (US \$) & Cost in (Euros) \\
\hline Hospital Bills & 42,333 & 263.05 & 238.66 \\
\hline ICU Setup & 17,9923 & 1129.91 & 1016.102 \\
\hline Staff Salaries & 2573 & 16.06 & 14.44 \\
\hline Grant Total & $\mathbf{2 2 , 4 8 2 2 9}$ & $\mathbf{1 4 0 9 . 0 2}$ & $\mathbf{1 2 6 9 . 2 0}$ \\
\hline
\end{tabular}

\section{DISCUSSION}

As predicted by the World Health Organization (WHO), that TBI will be the third largest disease after ischemic heart disease and depression leading to disability. ${ }^{9}$ The disabilities from traumatic brain injuries are usually demanding a protracted treatment, 
which impedes a financial burden on public sector hospitals. ${ }^{10}$ This study was conducted to present an estimate of an economic burden borne by the public section hospitals of Pakistan. Humphreys et al. (2013) ${ }^{9}$ mentioned regarding the cost of traumatic brain injury (TBI) and showed that the assessment of economic burden to TBI is relatively a new dimension which, is subjected to various attempts of quantification through a diverse methodology. Almost 1.4 million people suffer from TBI in US, ${ }^{11}$ but still there is a few published data regarding the economics and management related to an acute management of TBI patient. ${ }^{12}$ Faul et al. (2007) ${ }^{9}$ mentioned that the in 2002, an economic burden of traumatic brain injury was $\$ 60$ billion per annum in the US. We found that, the total cost of all major heads per day for six months (bills, ICU setup \& salaries) was only $\$ 1409$ in a public sector hospital of Pakistan. Schulman et al. $(2002)^{13}$ mentioned that in 1997 , total 107,000 cases of bicycle head injuries were reported in the US and $\$ 81$ million were spent in direct health costs, \$2.3 billion spent in indirect health cost for the preventable injuries. Our study showed that the Pakistani government's public sector hospitals are providing highly skilled consultancy to the patients in NCC (Neurocritical care unit) for just $\$ 1409$ /day, which is a peanut, when compared to the same level of consultancy and management provided in the developed countries. The total cost of Neurocritical drugs and routine investigations for all TBI patients in six months was $\$ 263 /$ day. For ICU beds, ventilators and monitors, the cost was $\$ 1130 /$ day. The total expenditure of medical staff salaries was $\$ 16.06$ per day. Kayani et al. (2009) ${ }^{14}$ mentioned that the annual cost for around twenty thousand TBI patient was $\$ 95$ million in total during 2001-2005 in Missouri.

The cost of any brain disorder varies according to the specific disorder. Cases of neuromuscular problems are found to be around $€ 30,000 /$ year. ${ }^{7}$ A study by Olesen et al. $(2011)^{7}$ mentioned that, in 2010 , the total cost of neurologic disorders was estimated $€$ 798 billion in Europe. This cost is no doubt is surprising. The data of WHO indicated that brain neurologic disorders covers almost one- third of the burden of all other ailments. Another Pakistan study was conducted by Siddiqui et al. (2015) ${ }^{15}$ in Aga Khan University Hospital, Karachi to calculate the hospital stay cost of severe head injury patients for an early tracheostomy and in endotracheal intubation procedures. They included the cost of emergency rooms, ICU beds, laboratory investigations and bills of the hospital. The total cost of early tracheostomy was $\$ 8027$ (49 patients) and $\$ 9961$ (51 patients) for endotracheal intubation in seven years. In 2009, a study was done by It was calculated that nearly 1.1 billion dollars annually are accounted for the productivity losses as a result of TBI related mortalities. ${ }^{14}$ Trauma foundation guidelines for the management of severe traumatic brain injury patients has reduced the cost of management of TBI patients. This was concluded in one of the studies that by following the guidelines of BTF (brain trauma foundation) not only the length of hospital stay can be reduced but also the charges for TBI. ${ }^{14}$

Although, a lot of work regarding the cost estimation for care of head injured patients had been done in the states and Europe. But, the still the solid estimates are missing in the literature. The underlying reason behind is the diversity of quantifiable variables. Our study is not just a financial evaluation of the burden of cost, but is also an eye opener for the health policy makers to allocate appropriate resources for the public sector hospitals. It can be inferred from our study that the health care facilities provided to TBI patients in Public sector hospital in Pakistan are much cheaper when compared to the private sector hospitals or the western world ${ }^{16}$. Services provided by the public sector hospitals in a developing country are often underestimated. The comparison of various studies done on the cost effectiveness/economic burden due to head injury patients revealed that the health care facilities in developing countries are contributing a cheaper option for the injury related health provision. The total cost of all major hospital cost heads per day in six months was only \$1409 in public sector hospital of Pakistan. These expenses were borne by the Pakistani government.

\section{CONCLUSION}

Our study relates the cost effectiveness of NCC (Neurocritical care unit) highlighting the economic burden born by the government and providing the best possible health care facilities despite resource constraints in developing countries. Our study highlighted an active role of public sectorphysicians, surgeons and paramedical staff in providing health care facilities at a cheaper rate.

\section{Limitation}

The exact assessment as a whole will take some more 
years of research, larger sample size and inclusion of the rest of other relevant parameters.

\section{Additional Information}

Disclosures: Authors report no conflict of interest.

Human Subjects: Consent was obtained by all patients/ participants in this study.

\section{Conflicts of Interest:}

In compliance with the ICMJE uniform disclosure form, all authors declare the following:

Financial Relationships: All authors have declared that they have no financial relationships at present or within the previous three years with any organizations that might have an interest in the submitted work.

Other Relationships: All authors have declared that there are no other relationships or activities that could appear to have influenced the submitted work.

\section{Address for Correspondence: Dr. Syed Shahzad Hussain Department of Neurosurgery Jinnah Hospital, Lahore - Pakistan Correspondence: Email: drshahzadns@yahoo.com}

\section{REFERENCES}

1. Scholten AC, Haagsma JA, Panneman MJ, Van Beeck EF, Polinder S. Traumatic brain injury in the Netherlands: incidence, costs and disability-adjusted life years. PLoS one, 2014; 9 (10): e110905.

2. Berg J, Tagliaferri F, Servadei F. Cost of trauma in Europe. European Journal of Neurology, 2005; 12: 8590.

3. Meerding WJ, Mulder S, Van Beeck EF. Incidence and costs of injuries in The Netherlands. The European Journal of Public Health, 2006; 16 (3): 271-7.

4. Polinder S, Meerding WJ, van Baar ME, Toet $\mathrm{H}$, Mulder S, van Beeck EF. Cost estimation of injuryrelated hospital admissions in 10 European countries. Journal of Trauma and Acute Care Surgery, 2005; 59 (6): 1283-91.

5. Schootman M, Buchman TG, Lewis LM. National estimates of hospitalization charges for the acute care of traumatic brain injuries. Brain injury, 2003; 17 (11): 983-90.
6. Runge JW. The cost of injury. Emergency medicine clinics of North America, 1993; 11 (1): 241-53.

7. Olesen J, Gustavsson A, Svensson M, Wittchen HU, Jönsson B, Group CS, et al. The economic cost of brain disorders in Europe. European journal of neurology, 2012; 19 (1): 155-62.

8. Ma VY, Chan L, Carruthers KJ. Incidence, prevalence, costs, and impact on disability of common conditions requiring rehabilitation in the United States: stroke, spinal cord injury, traumatic brain injury, multiple sclerosis, osteoarthritis, rheumatoid arthritis, limb loss, and back pain. Archives of physical medicine and rehabilitation, 2014; 95 (5): 986-95. e1.

9. Humphreys I, Wood RL, Phillips CJ, Macey S. The costs of traumatic brain injury: a literature review. Clinico-Economics and outcomes research: CEOR. 2013; 5: 281.

10. Faul M, Wald MM, Rutland-Brown W, Sullivent EE, Sattin RW. Using a cost-benefit analysis to estimate outcomes of a clinical treatment guideline: testing the Brain Trauma Foundation guidelines for the treatment of severe traumatic brain injury. Journal of Trauma and Acute Care Surgery, 2007; 63 (6): 1271-8.

11. Langlois JA, Rutland-Brown W, Thomas KE. Traumatic brain injury in the United States; emergency department visits, hospitalizations, and deaths, 2006.

12. McGregor K, Pentland B. Head injury rehabilitation in the UK: an economic perspective. Social science \& medicine, 1997; 45 (2): 295-303.

13. Schulman J, Sacks J, Provenzano G. State level estimates of the incidence and economic burden of head injuries stemming from non-universal use of bicycle helmets. Injury prevention, 2002; 8 (1): 47-52.

14. Kayani NA, Homan S, Yun S, Zhu BP. Health and economic burden of traumatic brain injury: Missouri, 2001-2005. Public health reports, 2009; 124 (4): 55160.

15. Siddiqui UT, Tahir MZ, Shamim MS, Enam SA. Clinical outcome and cost effectiveness of early tracheostomy in isolated severe head injury patients. Surgical neurology international, 2015: 6.

16. Farhad K, Khan HM, Ji AB, Yacoub HA, Qureshi AI, Souayah N. Trends in outcomes and hospitalization costs for traumatic brain injury in adult patients in the United States. Journal of neurotrauma, 2013; 30 (2): 8490 . 


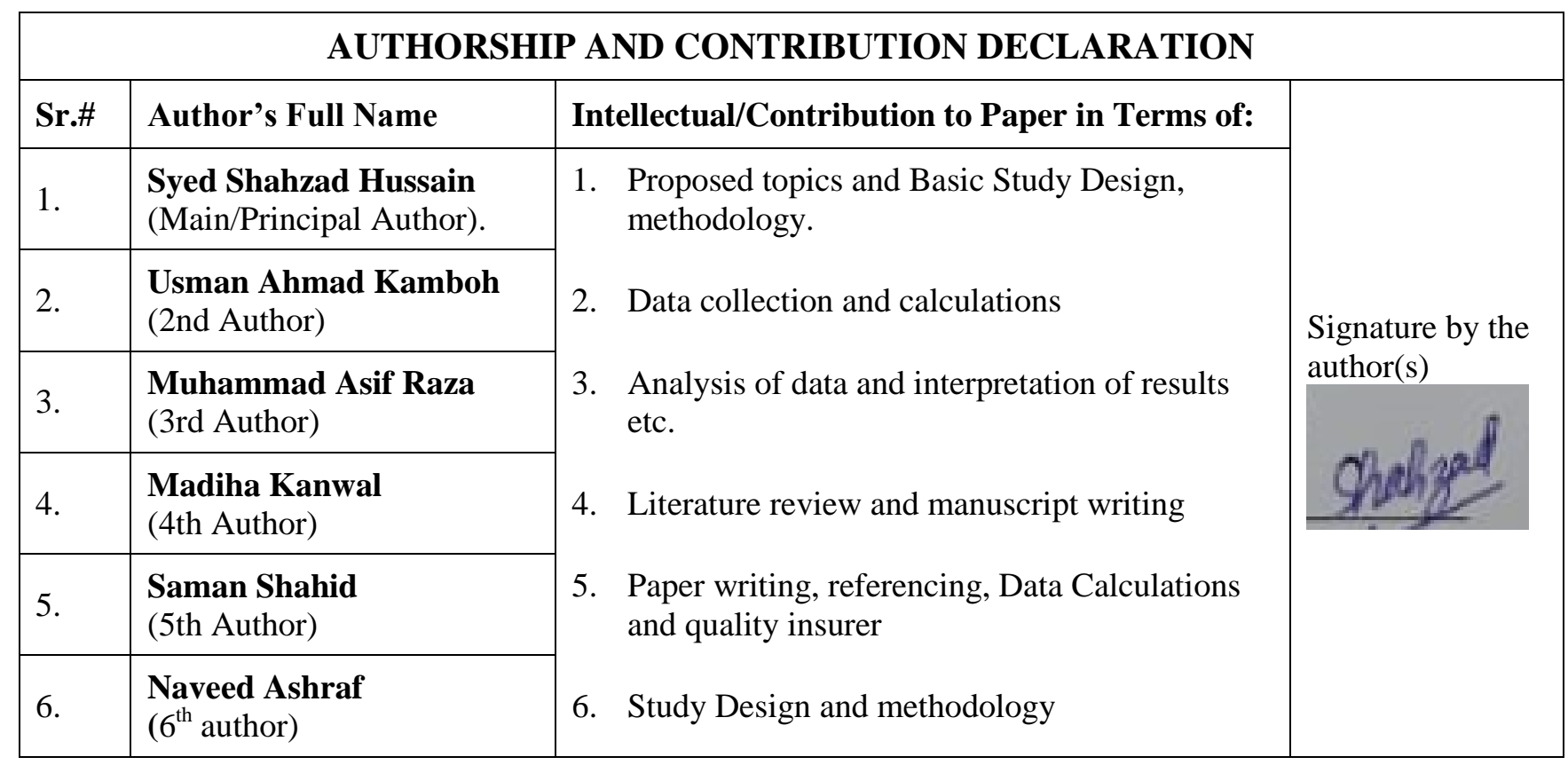

Date of Submission: 06-06-2019

Date of Revision: 25-07-2019

Date of Online Publishing: 25-09-2019

Date of Print: 30-09-2019 